\title{
Drivers of Farm Efficiency in Turkey: A Stochastic Frontier Analysis $^{1}$
}

\author{
Hasan Dudu² , Erol H. Çakmak ${ }^{3}$, Nadir Öcal ${ }^{4}$ \\ Received: 27/11/2015; Revised: 05/01/2015; Accepted: 07/01/2015
}

\begin{abstract}
This paper analyzes the efficiency structure of Turkish agriculture in farm household level by using various models of stochastic frontier analysis. A household level survey conducted in 2002 and 2004 is used in the analysis. Firstly, an efficient production frontier is estimated by a panel data model. By using these estimates, relative importance of inputs and their interaction with various farm characteristics are inspected. The parameters of production frontier show that agricultural production is crucially dependant on land and there is an excessive employment of labor. Secondly, the efficiency scores are estimated at farm household level. The results are reported according to NUTS-I regional classification and many other farm specific characteristics. The western parts of the country are found to be relatively more efficient and there is a high deviation in the mean efficiencies of different regions. There is an increase in mean efficiencies of all regions from 2002 to 2004. Besides, crop patterns, farm size, education level of household chief and irrigation are found to be effective on efficiency.
\end{abstract}

Keywords: Technical Efficiency, Turkish Agriculture, Stochastic Frontier Analysis

JEL Codes: Q10, Q12, D24

\footnotetext{
${ }^{1}$ This work was supported by TUBITAK (The Scientific and Technological Research Council of Turkey) as a part of SOBAG 1001-105K030 research project.

Disclaimer: The views expressed are purely those of the authors and may not in any circumstances be regarded as stating an official position of the European Commission.

${ }^{2}$ Corresponding Author, European Commission, Joint Research Center, Institute for Prospective Technological Studies, hasan@dudu.gen.tr

${ }^{3}$ TED University, Department of Economics

${ }^{4}$ Middle East Technical University Department of Economics
} 


\section{Introduction}

Agriculture has been on the reform agenda since mid-1990s in Turkey. The main motive was decreasing the burden of agricultural subsidies on the finances of the government. This burden was not only related to the budget, but also distributed through several funds and state economic enterprises, causing considerable difficulties for the financial discipline. Political and economic instability has postponed the reforms until the end of the decade. Economic crisis of 2001 made these reforms inevitable. Subsidization system has been changed substantially by Agricultural Reform Implementation Program (ARIP).

The focus of public discussions that are held just before and after 2001 economic crisis was on the macroeconomic implications of government intervention through the state economic enterprises and agricultural sales cooperatives to sustain a predetermined level of price. ARIP has largely been designed in response to these discussions. Although ARIP was a necessary step to transform the agriculture, it has not been sufficient to solve the main problems. ARIP was mainly concerned with macro structure of agriculture and it has not been supported by additional measures to create appropriate incentives to reform the microstructures such as production and marketing. However there are two important factors that Turkish agriculture will face in near future. Turkey has already started negotiations with EU and agriculture will be one of the most important fields in negotiations. On the other hand WTO commitments will become more and more binding and Turkish agriculture will be more vulnerable to international competition.

These three pillars, i.e. government finances, EU negotiations and WTO commitments, are closely related to the efficiency of production, in one way or the other. To alleviate the burden of support programs on the budget and on the consumers, macro level institutions should be designed to create necessary incentives for producers to increase their efficiency, since supporting inefficient producers cannot be a sustainable policy. Secondly, to be a decent member of the EU, Turkey needs to increase the efficiency in production since EU is not likely to accept to bear the cost of inefficiency of Turkish farmers from the common budget. Lastly, Turkish producers cannot compete with foreign producers under increased market access in domestic markets and in the international markets. Thus, any reform program that claims to unravel major issues in Turkish agriculture should give priority to the measures that will increase the efficiency of farmers in the core of its policies.

To shed a light on the discussions about the inefficiency levels of Turkish producers, first the concept of efficiency needs to be clarified. Literature on the structure of agricultural production in Turkey focuses on partial efficiency measures such as productivity of labor and yield of land rather than efficiency. There is an extensive literature that uses different partial efficiency measures to analyze the state of efficiency in Turkish agriculture. Only a few work use partial efficiency measures by acknowledging the difference between partial and technical efficiency measures such as Zaim and Çakmak (1998), Çakmak (2004), Kepenek and Yentürk (2001) Lundell et. al. (2004) while most of the others do not mention any difference at all, such as Özkan et. al. (2004) and Uzunlu, et. al. (1999). Some authors use extensive statistical methods to analyze partial efficiency such as Toksoy and Ayyıldız (2004) or employ simple econometric methods to obtain partial efficiency measures such as Akçay and Esengün (1999). On the other hand, rare quantitative work that follows recently developed methods in efficiency measurement literature use aggregate data such as Akder et. al. (2000) and Mahmud and Demir (1999 and 2002). In short, the difference between efficiency and productivity is generally ignored in the literature. Yields calculated by various methods are considered as measures of efficiency. Although one can make partial efficiency analysis and comparisons by using yields, a complete picture about the efficiency posture of households 
cannot be accessed merely by depending on information about yields since these measures do not give any information about relative ability of producers to utilize inputs.

Farrell (1957) is accepted to break new ground for the efficiency analysis by giving a comprehensive understanding of efficiency (Fare et al., 1985). Farrell (1957) criticizes the employment of partial efficiency measures "...due to a pure neglect of the theoretical side of the problem" (Farrell, 1957). Farrell (1957) provided a measure of efficiency that "...takes account of all inputs" yet avoids the deficiencies of partial efficiency measures. To do this, he calculated a production frontier from the "most efficient" observations in the first place. Then, he measured the efficiency of each observation with its distance from the estimated production frontier.

Models that use econometric methods to estimate the efficient frontier of Farrell (1957) are given the general name of stochastic frontier analysis (SFA). SFA depends on the idea that "...there exists some efficient frontier from which all the observed points deviate randomly but in the same direction" (Farrell, 1957). Afriat (1972) has stated the statistical foundations that were based on the deterministic model of Aigner and Chu (1968). Richmond (1974) discussed the modified ordinary least squares (MOLS) model to estimate efficiency scores by conventional econometric methods. Gabrielsen (1975) developed the corrected ordinary least squares (COLS) while Greene (1980a) used maximum likelihood estimation (MLE) methods to estimate the efficient frontier (Kumbhakar and Lovell, 2000). The current SFA models depend on the idea of modeling efficiency scores as composed error terms and this approach is simultaneously developed by Aigner, Lovell and Schmidt (1977), Meusen and Broeck (1977) and Battese and Corra (1977). Aigner, Lovell and Schmidt (1977) decomposed the error term to an independently and identically distributed "noise" which stands for the 'deviations from efficient frontier due to the chance factors and a one-sided error term that stands for the deviation from efficient frontier because of inefficiency" (Kumbhakar and Lovell, 2000).

Pitt and Lee (1981) extended cross-section analysis to panel data. Schmidt and Sickles (1984) applied panel data models by using fixed and random effects. Cornwell, Schmidt and Sickles (1990), Kumbhakar (1990) and Battese and Coelli (1992) introduced time-variable efficiency (Kumbhakar and Lovell, 2000). Lastly, technical efficiency effects models are introduced by Battese and Coelli (1995) to analyze the effect of factors that characterize the production process but are not among the arguments of production function. Battese and Broca (1997) has further developed technical inefficiency effects model to allow for nonneutrality between inputs and characteristic factors. A detailed survey about the topic can be found in Murillo-Zamorano (2004) while Kumbhakar and Lovell (2000) supply a comprehensive theoretical background.

In this paper, we attempt to figure out the general conditions under which Turkish agricultural sector operate. Section 2 will introduce a descriptive analysis of data that will be used in analysis. In Section 3 we will use stochastic frontier methods to analyze the efficiency structure of Turkish agriculture. The last chapter is reserved for concluding remarks.

\section{Data}

The data set used in this study is unique. It is based on Quantitative Household Survey (QHS) commissioned by the Treasury and implemented by the G.G. Consulting et al. (2002 and 2004) to observe the effects of Agriculture Reform Implementation Program (ARIP). Approximately 2700 variables are obtained from the survey results. Originally, 5508 households are participated in survey. The survey is conducted for the years 2002 and 2004. 
We used the production section of the questionnaire for 3014 farm households ${ }^{5}$. The data set is classified using the NUTS-I definition of Turkish Statistics Institute. Table 1 gives the mean values of the variables used in estimation.

Total revenue from crop and livestock production is used as dependent variable. Labor expressed as days worked is used as labor data. The unpaid labor used in agricultural activities is not given in survey results for 2004. Thus, labor use per hectare for 2002 is used as a proxy for the same figure for 2004. This excludes any effect of introduction of labor saving technologies on efficiency. However, given the short span of time, this is not likely to introduce any serious bias in results. All observations that used zero labor (hence, zero land used in 2004) are excluded from the analysis. Land data consists of total dry and irrigated land used for field crops, dry and irrigated land used as orchards and fallow land in hectares. Livestock data is in Bovine Unit which is defined by ministry of Agriculture and Rural Affairs, and consists of the number of animals that the households own.

Table 1: Means of input variables used in analysis

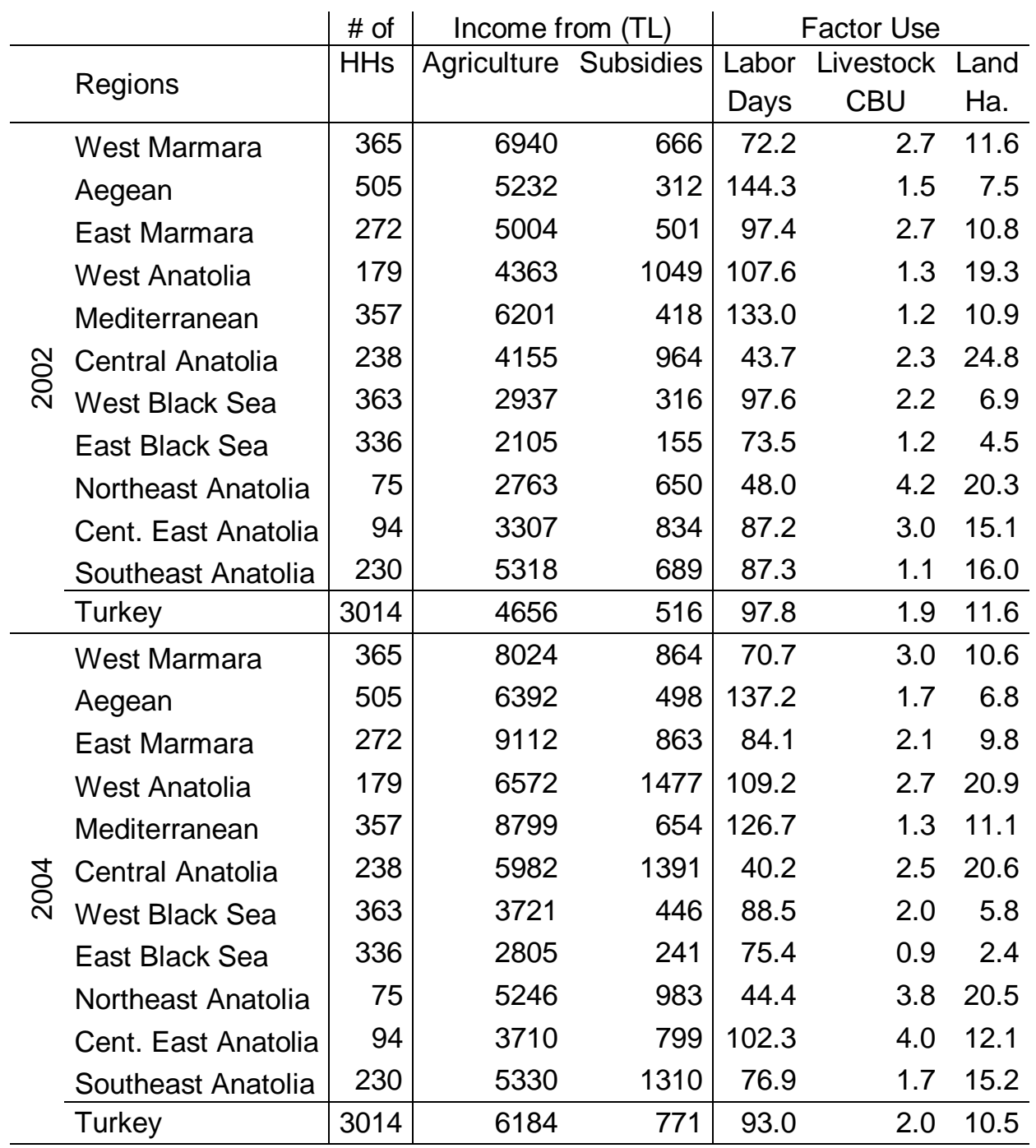

Source: Author's calculations from G.G.C. et. al. (2003 and 2005)

51358 households which are replaced with the nearest neighbors and 1104 households, whose answers are contradicting, are excluded from the analysis. 
Table 1(continued): Means of input variables used in analysis

\begin{tabular}{|c|c|c|c|c|c|c|c|c|c|}
\hline & \multicolumn{9}{|c|}{ Money spent on (TL) } \\
\hline Regions & Seed & Fertilizer & Pesticide & Water & Diesel & Electricity & Other & Feed & Total \\
\hline West Marmara & 312 & 997 & 206 & 48 & 1118 & 55 & 1085 & 1054 & 4875 \\
\hline Aegean & 172 & 531 & 322 & 188 & 922 & 108 & 745 & 497 & 3484 \\
\hline East Marmara & 269 & 747 & 236 & 143 & 1231 & 123 & 841 & 564 & 4155 \\
\hline West Anatolia & 442 & 1180 & 184 & 408 & 1765 & 224 & 767 & 499 & 5469 \\
\hline Mediterranean & 1063 & 1472 & 759 & 273 & 1214 & 58 & 721 & 418 & 5978 \\
\hline Central Anatolia & 193 & 1348 & 149 & 67 & 1642 & 62 & 749 & 319 & 4531 \\
\hline West Black Sea & 236 & 479 & 176 & 51 & 705 & 20 & 510 & 276 & 2455 \\
\hline East Black Sea & 25 & 329 & 53 & 4 & 56 & 13 & 100 & 227 & 806 \\
\hline Northeast Anatolia & 222 & 334 & 1006 & 86 & 903 & 13 & 762 & 252 & 3578 \\
\hline Cent. East Anatolia & 104 & 314 & 59 & 26 & 386 & 25 & 650 & 346 & 1910 \\
\hline Southeast Anatolia & 408 & 807 & 275 & 133 & 658 & 163 & 809 & 205 & 3459 \\
\hline Turkey & 329 & 802 & 288 & 132 & 955 & 78 & 696 & 457 & 3738 \\
\hline West Marmara & 152 & 1962 & 352 & 75 & 1064 & 44 & 950 & 1186 & 5785 \\
\hline Aegean & 173 & 869 & 512 & 374 & 974 & 134 & 1227 & 636 & 4900 \\
\hline East Marmara & 149 & 1425 & 571 & 248 & 1012 & 33 & 929 & 760 & 5127 \\
\hline West Anatolia & 570 & 1640 & 295 & 679 & 1953 & 615 & 1429 & 747 & 7930 \\
\hline Mediterranean & 717 & 1917 & 746 & 425 & 870 & 117 & 1318 & 344 & 6454 \\
\hline Central Anatolia & 205 & 1720 & 319 & 267 & 1424 & 60 & 932 & 362 & 5290 \\
\hline West Black Sea & 69 & 675 & 232 & 114 & 636 & 18 & 331 & 250 & 2325 \\
\hline East Black Sea & 13 & 385 & 27 & 35 & 35 & 1 & 147 & 119 & 762 \\
\hline Northeast Anatolia & 216 & 766 & 59 & 428 & 581 & 76 & 888 & 608 & 3622 \\
\hline Cent. East Anatolia & 38 & 469 & 247 & 0 & 351 & 3 & 167 & 286 & 1561 \\
\hline Southeast Anatolia & 249 & 1484 & 321 & 171 & 509 & 200 & 679 & 314 & 3927 \\
\hline Turkey & 231 & 1243 & 376 & 247 & 860 & 106 & 854 & 524 & 4441 \\
\hline
\end{tabular}

Source: Author's calculations from G.G.C. et. al. (2003 and 2005)

Expenditures on seed, fertilizers, pesticides, irrigation, diesel, electricity, animal feed and other operational costs are also included as explanatory variables. Survey results do not report any quantities for these inputs. Using these figures incorporates the information about input prices by ignoring the differences in prices paid by the households among regions. Though, prices of these items are not likely to vary much through out the country since there is no price difference among regions in diesel, electricity, fertilizers, animal feed and pesticides, apart from the transportation costs. Besides the markets of these inputs are integrated enough to assume a small deviation among regions in the prices of these items. There are many work in the literature that use money paid to inputs in similar cases. ${ }^{6}$

The inefficiency effects are incorporated by six groups of variables. The mean values of selected factors that affect the production structure are given in Table 2.

\footnotetext{
${ }^{6}$ To count a few, Batesse, Rao and O'Donnell (2004), Batesse and Coelli (1995), Chavas, Petrie and Roth (2005) use money spent on inputs instead of quantity in the estimation of frontier.
} 
Table 2: Mean values for some factors that characterize the production structure

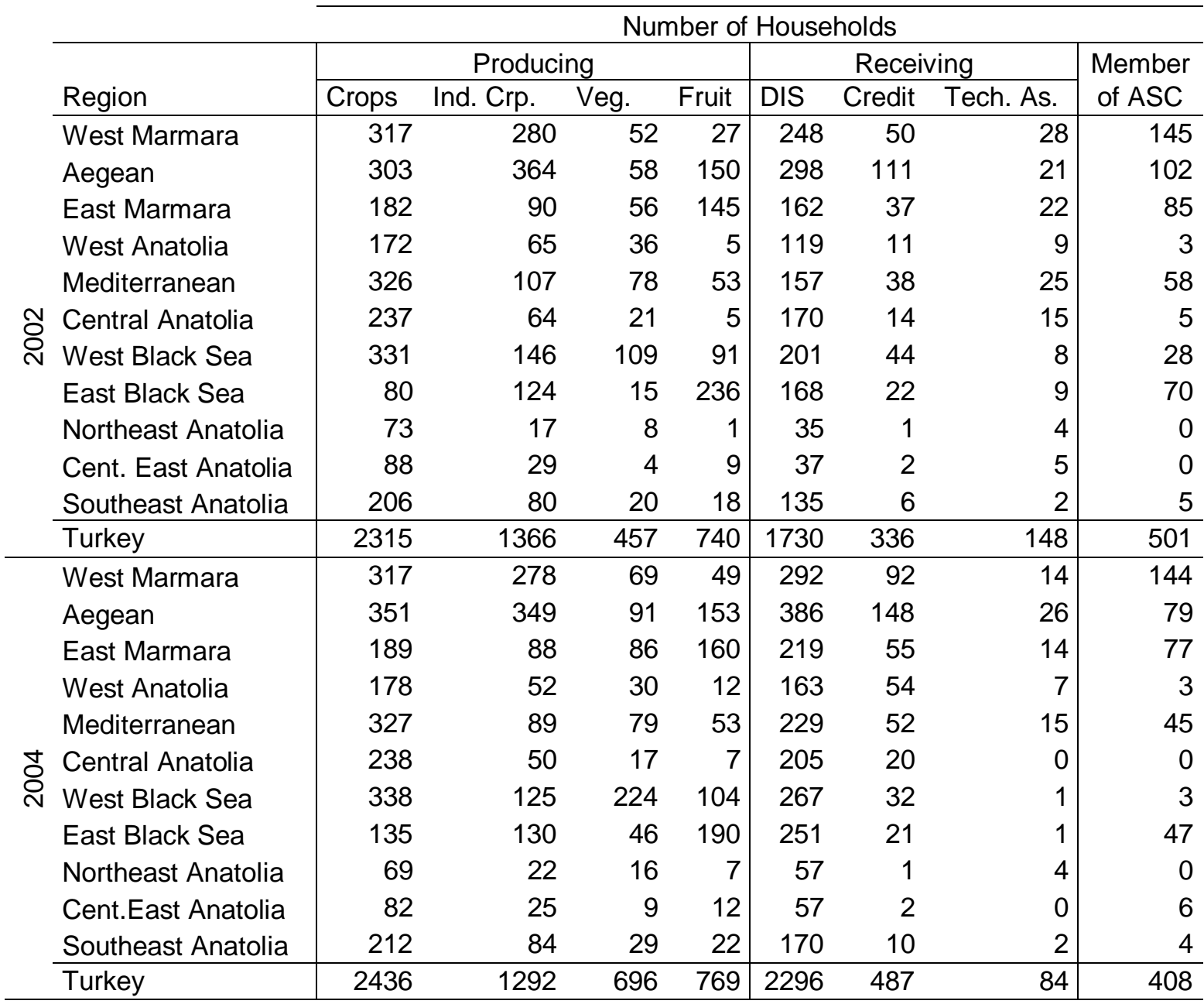

Source: Author's calculations from G.G. et. al. (2003 and 2005)

The first group is composed of five variables related to land. The share of irrigated land, orchards, fallow, rented land and land taken for sharecropping in total land are included in this group of variables. The second group consists of four dummy variables for the production pattern of household. These variables take the value one if the household is producing the related crop. The third group consists of dummy variables for DIS receiving, credit access, technical support access and Agricultural Sales Cooperative Union membership status of households.

The fourth group consists of three dummy variables about the education status of household chief. The first variable takes value one if household chief is illiterate and zero otherwise while the second variable takes value one if the household chief has a primary school degree and zero otherwise. For the households of which chief has a higher education the third variable takes the value one. The fifth group of variables are related to the farm size and consists of six dummy variables respectively for 0-2 Ha., 2-5 Ha., 5-10 Ha., 10-20 Ha., 20-50 Ha. and more than $50 \mathrm{Ha}$. of land area owned. The variables take value one if the total area of land owned by the household is in the related size group. The last group of variables consists of region dummies at NUTS-I level. If household is in the relevant NUTS-I region then the variable takes value one and zero otherwise. 
Table 2 (continued): Mean values for some factors that characterize the production structure

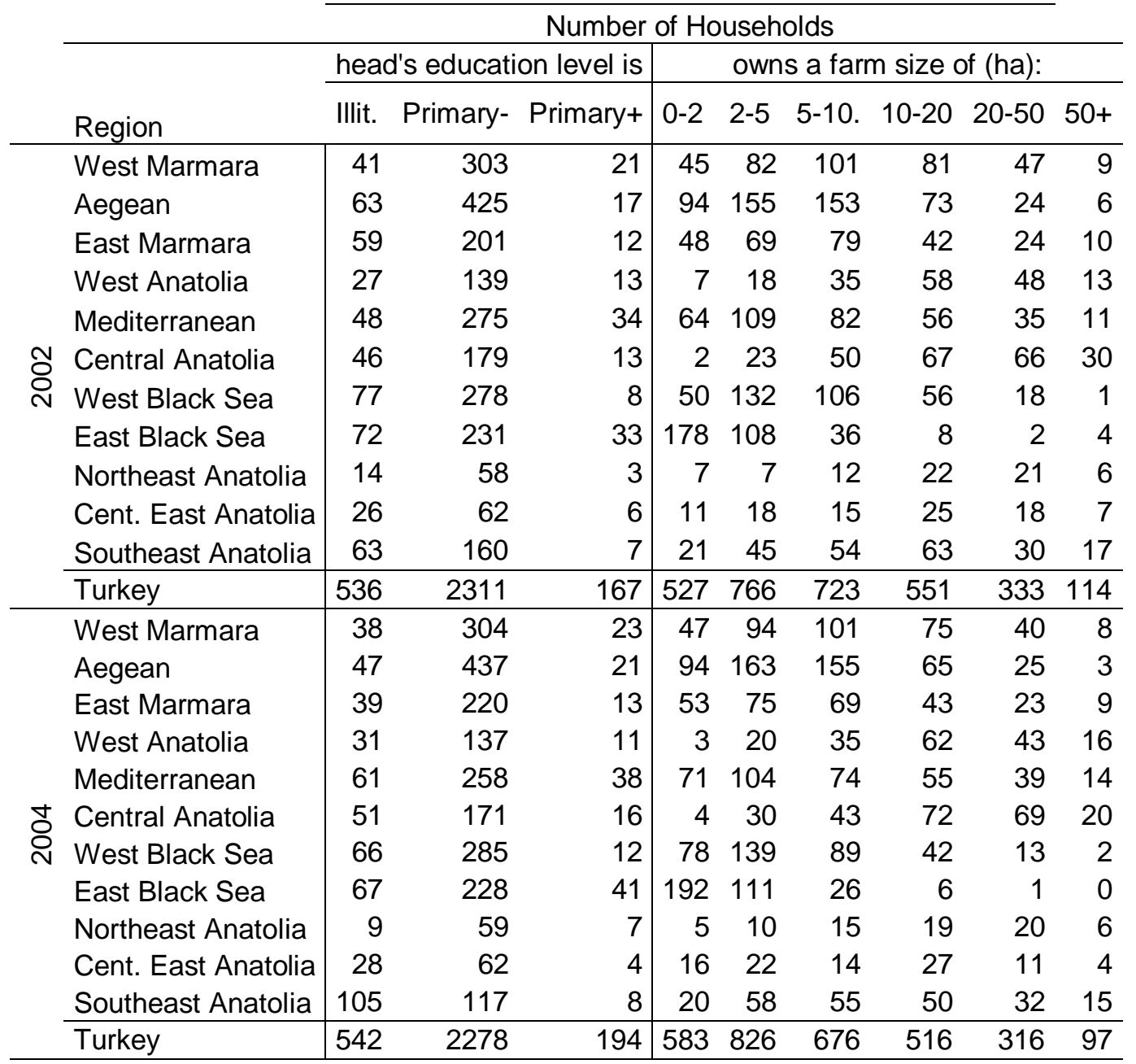

Source: Author's calculations from G.G. et. al. (2003 and 2005)

\section{Model and Estimations}

Stochastic frontier models are applied to the data described above. The deviation from the efficient frontier is modeled by a compound error term. The compound error term is sum of a normally distributed noise term and an asymmetrically distributed "inefficiency" component, which is always negative. The negative component represents the deviations of the firms from the efficient frontier due to inefficient structure of production while the normally distributed term stands for the random deviations from the efficient frontier due to reasons such as data measurement errors.

The most general form of the stochastic frontier model can be written as

$$
Y=F(X ; \beta) \exp (v-u)
$$

where,

$$
\begin{gathered}
v \sim N\left(0, \sigma_{v}^{2}\right) \\
u \sim\left|N\left(0, \sigma_{u}^{2}\right)\right|
\end{gathered}
$$


Normally distributed component of composite error term, $v$, and the inefficiency component of the error term, $u$, are distributed identically and independently from each other and regressors. $Y$ is a one by $i x t$ vector of output level. $F($.$) is the imposed functional form$ of frontier and it takes $X$ as argument. $X$ is a $k+l$ by $i$ x $t$ matrix and composed of a column of ones and $k$ input variables. $\beta$ is a one by $k+1$ vector of parameters. $u$ and $v$ are one by $i \mathrm{x}$ $t$ vectors of inefficiency and random components, respectively.

Production technology is assumed to follow a translog functional form. To obtain input elasticities at the sample mean directly from the estimated coefficients, input data is transformed to deviations from the geometric mean.

The model used in this paper is originally introduced by Batesse Coelli (1995). The model depends on a former modification of (1) developed in Batesse and Coelli (1992) to allow for time-varying efficiency to incorporate the change in firm level efficiency over time in quite elastic way as follows

$$
u_{i t}=u_{i} \cdot \theta(t)
$$

and

$$
\theta(t)=\exp (\gamma(t-T))
$$

The distributional assumptions are same as in (2) and (3). The major contribution of the model in Batesse and Coelli (1992) is the introduction of time dimension for firm level efficiency in a quite simple way. Only one extra parameter, namely $\gamma$, is estimated to find varying efficiencies over time. The details of the model and estimation process can be found in Battese and Coelli (1992).

Estimation of technical inefficiency does not have much policy implications by itself. The model developed in Batesse and Coelli (1992) estimates the relationship between input utilization of firms and their output. However, they do not give any explanation about the reasons of inefficiency. Unraveling the factors underlying inefficiency is as important as estimating inefficiency for policy design. The early work on efficiency analysis has incorporated such factors into the analysis by running a second step regression. In this second step, efficiency scores are regressed on these exogenous variables by using OLS. However, this approach turns out to be problematic since when estimating the efficiency scores one assumes identically distributed $u$ (Battese and Coelli, 1995).

Battese and Coelli (1995) employ a single step approach that will not contradict with the identical distribution assumption about $u$ while explaining the technical inefficiency effects. They modify the model developed in Battese and Coelli (1992) by making the following assumption:

$$
u_{i t}=\sum_{i=1}^{k} \delta_{i} z_{i t}+w_{i t}
$$

where $z_{i t}$ s are exogenous variables, $\delta_{i}$ s are parameters to be estimated and $w_{i t}$ is identically and independently distributed as $N\left(0, \sigma_{w}\right)$. To be compatible with the model of Battese and Coelli (1992) we need to impose the following condition on $u_{i t}$

$$
u_{i t}=\sum_{i=1}^{k} \delta_{i} z_{i t}+w_{i t} \geq 0
$$


which in turn implies

$$
w_{i t} \geq-\sum_{i=1}^{k} \delta_{i} z_{i t}
$$

and this implies

$$
u_{i t} \sim\left|N\left(-\sum_{i=1}^{k} \delta_{i} z_{i t}, \sigma_{w}\right)\right|
$$

The parameters of the model defined by equations (1)-(3) and (6)-(9) can be estimated by using maximum likelihood estimation techniques (Battese and Coelli, 1995). The $\delta$ coefficients show the marginal effect of exogenous variables on technical efficiency ${ }^{7}$.

\section{Findings}

The results of the tests that are conducted using the findings of these models are summarized in Table 3. The paremeters $\sigma^{2}$ and $\gamma$ are statistically significant at 1 percent significance level that implies to the existence of a significant technical inefficiency among the households. Time invariant technical inefficiency is also rejected since the coefficient of time dummy is statistically significant for both models.

\begin{tabular}{|c|c|c|c|}
\hline $\begin{array}{c}\text { Test } \\
\end{array}$ & $H_{0}$ & Test Statistic & Result \\
\hline \multirow{2}{*}{$\begin{array}{l}\text { Existence of technical } \\
\text { inefficiency across farms }\end{array}$} & $\sigma^{2}=0$ & -3.65 & Reject \\
\hline & $\gamma=0$ & 3.91 & Reject \\
\hline Time Invariant Efficiency & $\delta_{t}=0$ & 171.59 & Reject \\
\hline \multirow{2}{*}{$\begin{array}{l}\text { Significance of Technical } \\
\text { Inefficiency Variables }\end{array}$} & \multirow{2}{*}{$\begin{array}{l}\delta_{i}=0 \\
\text { for all } i\end{array}$} & 415.50 & Reject \\
\hline & & 629.697 & Reject \\
\hline \multirow[t]{2}{*}{ Constant Returns to Scale } & $\sum$ & 1.32 & \\
\hline & $\sum \beta=1$ & 30.2 & Reject \\
\hline
\end{tabular}

Table 3: Test Results

Source: Author's calculations from G.G. et. al. (2003 and 2005)

Significance of technical inefficiency effects variables is tested for both models by Wald test and likelihood ratio test. Both test statistics for N-TIEM are larger than the critical value of $\chi_{31}^{2}=44.99$. The critical value for NN-TIEM is $\chi_{341}^{2}=385.062$, and it is smaller than the test statistics. Thus, null hypothesis is strongly rejected by both tests for both models. Accordingly, it can be concluded that technical inefficiency is explained by the technical inefficiency effects variables and TVDM is not an appropriate specification to measure the technical inefficiency. Significance of cross terms is tested by a Wald test. Test statistic turns out to be 445.27 while the critical value is $\chi_{341}^{2}=379.75$. Thus, the Wald test statistic rejects the null hypothesis of insignificant cross terms. CRS is strongly rejected in N-TIEM. Sum of coefficients of inputs is 1.32 and this implies increasing returns to scale. Test statistic for CRS is 2.19 which is smaller than $\chi_{1}^{2}=3.94$. Thus, NN-TIEM model fails to reject CRS. Sum of coefficients of input variables is 1.12 and it is not statistically different from one.

\footnotetext{
${ }^{7}$ We have also estimated the model in Batesse and Coelli (1992) to test the significance of the efficiency effect variables and the model developed in Batesse and Broca (1997) is also estimated but not presented. The results of two models are consistent and the latter are reported in Dudu (2006) and Çakmak et al. (2008).
} 
Coefficients of input variables are reported in Table 4. Coefficients of inputs are positive and statistically significant except for labor in N-TIEM model. Insignificance of labor can be explained by measurement problems described afore. Besides, many authors report insignificant coefficients of labor for various countries. To count a few, work of $\mathrm{Xu}$ and Jeffrey (1998) for Chinese rice production, Coelli, Rahman and Thirtle (2003) for Bangladeshi crop production and Mahmud and Demir (2002) for Turkish agricultural sector, report insignificant coefficients for labor. Xu and Jeffrey (1998) relate insignificance of labor to the extension in modern input usage while Coelli, Rahman and Thirtle (2003) explain the same fact with labor surplus in these economies. Mahmud and Demir (2002) explain their finding by excessive usage of labor in Turkish agriculture. Both explanations are appropriate for Turkish case since descriptive statistics depicts the extension in modern input usage and the existence of excess labor in Turkish agricultural sector is a well-known fact (Çakmak et. al. 2004).

\section{Table 4: Estimated coefficients for input variables}

\begin{tabular}{|c|c|c|c|}
\hline Variable & Coefficient & Std. Err & \\
\hline Constant & 7.92 & 0.10 & $\star \star * \star$ \\
\hline Labour & 0.07 & 0.04 & \\
\hline Livestock & 0.05 & 0.01 & *** \\
\hline Land & 0.38 & 0.04 & *** \\
\hline Seed & 0.03 & 0.01 & *** \\
\hline Fertilizer & 0.33 & 0.04 & *** \\
\hline Pesticides & 0.15 & 0.02 & *** \\
\hline Water & 0.02 & 0.01 & *** \\
\hline Diesel & 0.17 & 0.02 & *** \\
\hline Electricity & 0.02 & 0.00 & *** \\
\hline Other Costs & 0.04 & 0.02 & ** \\
\hline Animal Feed & 0.07 & 0.01 & *** \\
\hline
\end{tabular}

Land turns out to be the most important factor of production with an output elasticity of 0.38. Underlying reason for land being the most important input to affect the agricultural production can be insufficiency of modern infrastructure and technological progress. Accordingly, agricultural production has remained to be crucially dependant on land. Agricultural policies followed since the establishment of the Republic has always considered extension of cultivated area as the most important source of agricultural output growth in Turkey (Çakmak and Akder, 1999). Governments had supported the cultivation of even marginal areas with limited potential yield.

Fertilizer, diesel and pesticides follow the land as inputs with significantly higher elasticities. This offers that fertilizer, diesel and pesticides are the most important source of increase in the yield of land. Agricultural policies followed after 1960s confirms this conclusion. After agricultural land has reached its feasible frontier in terms of area, governments had focused on increasing the yield of land by encouraging farmers to use modern inputs more extensively (Çakmak and Akder, 1999). Several input subsidy programs are held for this purpose.

Second group of inputs that are relatively more effective on agricultural output is animal feed, livestock and other costs that mainly consist of expenditure on fodder. Output elasticities of these inputs are much smaller than that of the land and land related inputs. This points out that dairy production does not contribute as much as vegetal production to the agricultural revenue. Besides, the output elasticity of number of livestock is smaller than that of animal 
feed. Therefore, one can characterize households in two groups according to livestock ownership. Households that use animal feed are likely to be more market oriented while others are likely to consider livestock holding as a kind of investment. Thus, animal feed turns out to be more important for agricultural revenue. This turns out to be rational when the insufficiency of social security network that covers the rural households is taken into account. Since most of the small farmers are left outside the social security system, they invest on livestock in order to use it in "bad days". The financial instruments can be quite problematic for households. One possible problem may be prohibition of interest bearing assets by the religion. Secondly, the financial instruments are complicated for most of the household chiefs who does not have an education further than primary school. The last but not the least, the availability of financial intermediaries is quite limited in the rural areas (Çakmak et. al. 2004). Lower output elasticity of other costs supports this hypothesis since fodder is the main component of other costs and it is the "cheaper" way of feeding livestock. Naturally, there is a trade off between the yield of livestock and cost of feeding. Since the households that do not care much about the amount of dairy production are also likely to use fodder instead of animal feed.

The last group of inputs that are less effective on agricultural revenue is composed of seed, water and electricity. Since money spent on seed is used as independent variable, importance of seed usage in production process can be underestimated. The seed variable does not comprise any information about seed usage in view of the fact that households are likely to use self-produced seeds, especially for cereal production where seeds are among the main inputs. Despite the underestimation problem, low output elasticity of money spent on seeds reveals and important fact. Money spent on seeds covers the cost of buying highqualified seeds. Low output elasticity of this variable recommends that high quality seeds are not as effective as other inputs in increasing the production.

Underestimation problem also prevails in water and electricity usage that are mainly used for irrigation. There is a registration and pricing problem in irrigation from the water channels managed by the state institutions or irrigation associations. In most cases, farmers are let to use these facilities at low fees to encourage irrigation that results in the overuse of water. Similar problems also exist in electricity usage. Descriptive statistics for money spent on water and electricity and share of irrigated land substantiate these conclusions.

Coefficients of inefficiency effects variables are as expected and most of them are significant at conventional levels of significance (Table 5). Coefficient of share of irrigated land and orchards is negative and significant indicating a positive effect of irrigation on efficiency. This result is in line with expectations since irrigation is expected to increase the yield of land and products of orchards have higher value added. Share of fallow land is positive and significant indicating a negative effect on efficiency. This is also expected since the model considers that the alternative cost of fallow land is not cultivating some part of land and thus giving up some output.

Coefficients of dummy variables which designate the dominant products of the farm households are all in expected signs and significant at the conventional levels of significance. Being a producer of cereals affects efficiency negatively. This is not surprising especially under the production technology prevailing in Turkey. Another possible explanation can be made by considering the long lasting distortions of price support policies that has weaken the sensitivity of producers to market signals. Hence, efficiency has not been a criterion for survival of cereal producers and all kinds of investments both on physical capital and technological progress are ignored for a long time. Reforms made by ARIP turn out to be ineffective in increasing the efficiency of cereal producers. 
Table 5: Estimated coefficients for technical efficiency effects variables

\begin{tabular}{|c|c|c|c|c|c|c|c|}
\hline Variable & Coeff. & \multicolumn{2}{|c|}{ Std. Error } & Variable & Coeff. & \multicolumn{2}{|c|}{ Std. Error } \\
\hline Constant & 1.59 & 0.15 & 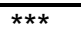 & West Anatolia & 0.09 & 0.08 & \\
\hline Irrigated & -0.08 & 0.01 & *** & Mediterranean & -0.34 & 0.07 & 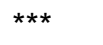 \\
\hline Orchard & -0.06 & 0.01 & 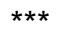 & Central Anatolia & 0.05 & 0.07 & \\
\hline Fallow & 0.05 & 0.01 & *** & West Black Sea & 0.05 & 0.07 & \\
\hline Rented & 0.04 & 0.01 & *** & East Black Sea & -0.14 & 0.09 & \\
\hline Sharecropper & 0.01 & 0.00 & *** & Northeast Anatolia & 0.19 & 0.10 & * \\
\hline Cereals & 0.27 & 0.05 & *** & Central East Anatolia & 0.07 & 0.09 & \\
\hline Ind. Crops & -0.34 & 0.04 & *** & Illiterate & 0.35 & 0.08 & $\star \star \star *$ \\
\hline Vegetable & -0.08 & 0.04 & ** & Literate or Primary & 0.17 & 0.07 & ** \\
\hline Fruit & -0.08 & 0.05 & ** & Size 2-5 Ha. & -0.12 & 0.05 & ** \\
\hline DIS & -0.02 & 0.03 & & Size 5-10 Ha. & -0.23 & 0.07 & *** \\
\hline Credit & -0.04 & 0.05 & & Size $10-20 \mathrm{Ha}$. & -0.40 & 0.09 & $* * *$ \\
\hline Tech. Sup. & -0.05 & 0.08 & & Size $20-50 \mathrm{Ha}$. & -0.54 & 0.11 & $* * *$ \\
\hline ASC & -0.10 & 0.05 & * & Size 50+ Ha. & -0.73 & 0.15 & $* * *$ \\
\hline West Marmara & -0.40 & 0.08 & $\star * *$ & Time & -0.52 & 0.04 & $* * *$ \\
\hline Agean & -0.14 & 0.07 & $\star *$ & $\ln \sigma^{2}$ & -0.14 & 0.04 & $\star \star \star *$ \\
\hline East Marmara & -0.27 & 0.08 & $* * *$ & $\ln \gamma$ & 0.55 & 0.14 & $\star \star \star *$ \\
\hline
\end{tabular}

Source: Author's calculations from G.G. et. al. (2003 and 2005)

Being in one of the other producer groups effects efficiency positively. Effects of vegetable and fruit production are close to each other while the effect of industrial crops is considerably higher.

Coefficients of DIS receiving status, credit access and technical support receiving status are negative but insignificant. Insignificance of these variables offers that these factors cannot explain the variation in efficiency. Thus, it may reasonable to question the success of DIS program and quality of credit access and technical support services. The implementation period of DIS was too short (only three years) to give final verdict. Nevertheless, one would expect farmers to move closer to the efficient frontier as the distortionary price support and other production based subsidy programs are cancelled. Another factor that limited the impact of DIS is the fact that the distortionary support picked up in 2003 and 2004, hence limiting its expected impact. Moreover, DIS program, by itself, is not designed to create any incentive for inefficient farmers to be more efficient. The program is introduced to compensate the revenue losses of farmers due to the cancelled subsidy programs. So any efficiency improvements that occurred because of ARIP cannot be observed in the coefficient of DIS variable. Insignificance of effect of DIS variable on efficiency depicts that households who received support did not or could not use this money to improve their efficiency, or they used it for this purpose but its effects cannot be observed yet. Both are possible when the irregularities and delays in payments are taken into account. Farmers cannot finance their investments, especially the long-term investments that are likely to be more effective on efficiency, by relying on frequently delayed DIS payments.

Coefficient of being a member of agricultural sales cooperative unions (ASCUs) is negative and significant at 10 percent level. This is something expected since members of ASCUs are still likely to have a better access to the market even during the restructuring period of the ASCUs.

Region dummies compare the effect of being at the designated region compared to being in Southeast Anatolia. Thus, smaller coefficients imply a better effect on efficiency weighed against the effect of being in Southeast Anatolia. In line with expectations, being in the 
western and southern parts of the country has a significant and positive effect on efficiency. The coefficients of other regions are insignificant suggesting that effect of being in these regions is not statistically different from being in Southeast Anatolia.

Coefficients of education level variables compare the effect of being illiterate and being literate or having a primary school degree with that of having a degree higher than primary school. Both coefficients are significant and positive indicating a negative effect on efficiency. As education level falls efficiency gets worse off.

Coefficients of size dummies compare the effect of corresponding farm size with that of 0-2 Hectares size group. Coefficients depicts that the efficiency of household increases as their farm size grows. This is consistent with the test results that depict increasing returns to scale on the efficient frontier.

Lastly, the time dummy recommends that the efficiency has increased over time. Although time dimension of data is small, this can be taken as implication of positive effect of ARIP and macroeconomic stability that persist since 2002 .

To sum up, estimated frontier reflects the many characteristics of agricultural production in Turkey. The output elasticities of input variables reflect a conventional production function in which land and the inputs that are used to enhance the yield of land play a major role. The coefficients of technical inefficiency effects variables are in line with expectations and justify most of the conventional standpoints. The interactions between inputs and technical inefficiency effects variables reveal some important facts such as the efficiency impeding effect of irrigation by electrical pumps or low quality of technical support or significance of livestock production for the efficiency of different household groups.

Descriptive statistics for estimated efficiency scores for NUTS-I regions are given in Table 6. There is a significant increase in the efficiencies from 2002 to 2004 . This increase offers an increased integration of households to market. The increase is highest in western and southeastern parts of the country. East Marmara leads the increase with 22.78 percent. It is followed by Northeast Anatolia with 16.09 percent, West Marmara with 14.11 percent, Aegean with 13.34 percent and East Black Sea with 13.25 percent. Increase in the central parts of the country is around 10 percent while it is lowest with 8.31 percent in Central East and 5.42 percent in Southeast Anatolia.

Agricultural production in the western parts of the country is more efficient. Ranking of regions changes from 2002 to 2004. West Marmara, Aegean and East Marmara regions are in the first three ranks in both in 2002 and 2004. Mediterranean and East Black Sea regions share the $4^{\text {th }}$ and $5^{\text {th }}$ place in both years. Ranking of regions in central parts of the country, namely West, Central, Central East Anatolia and West Black Sea also did not change significantly. However, there has been a significant change in the ranking of Northeast and Southeast Anatolia. Northeast Anatolia has soared to sixth position from 11, and Southeast Anatolia has felt to 11 in 2004 while it was $6^{\text {th }}$ in 2002 . This drastic change can be explained by increasing protection in meat that is the main product of Northeast Anatolia, as suggested by descriptive statistics of number of livestock. On the other hand, the plummet of Southeast Anatolia is probably due to the rigidity of the region to the changes in the macro and agricultural policy environment. 
Table 6: Mean efficiency scores

\begin{tabular}{lcc|cc}
\hline \multirow{2}{*}{ Region } & \multicolumn{2}{c|}{ Average } & \multicolumn{2}{c}{ Std. Dev. } \\
\hline West Marmara & 2002 & 2004 & 2002 & 2004 \\
Agean & 37.9 & 50.6 & 16.2 & 16.8 \\
East Marmara & 34.8 & 45.4 & 18.3 & 17.4 \\
West Anatolia & 32.3 & 52.4 & 17.4 & 18.2 \\
Mediterranean & 24.0 & 33.3 & 13.2 & 16.5 \\
Central Anatolia & 34.1 & 46.8 & 18.1 & 19.4 \\
West Black Sea & 22.6 & 32.8 & 13.2 & 15.3 \\
East Black Sea & 23.4 & 34.4 & 13.3 & 15.1 \\
Northeast Anatolia & 33.4 & 46.5 & 14.5 & 17.2 \\
Central East Anatolia & 19.8 & 33.7 & 10.6 & 17.4 \\
Southeast Anatolia & 24.6 & 32.6 & 13.4 & 17.1 \\
Turkey & 27.4 & 33.2 & 16.6 & 17.2 \\
Source: Author's calculations from G.G. et. al. & \multicolumn{3}{|c}{$(2003$ and 2005$)$}
\end{tabular}

Standard deviation of the efficiency for the whole sample is around 18-20 percent. Standard deviation is higher in western regions while it increases significantly in eastern parts of the country from 2002 to 2004. Increase is highest in Northeast and Central East Anatolia. Standard deviation in central parts of the country is lower in both periods.

Mean efficiencies for several groups of households defined by technical inefficiency effects variables are given in

Table 7.

Table 7: Mean efficiencies for groups of households defined by technical inefficiency variables

\begin{tabular}{llrr|rr}
\hline & & \multicolumn{2}{c|}{ Average } & \multicolumn{2}{c}{ Std. Dev. } \\
& & $\mathbf{2 0 0 2}$ & $\mathbf{2 0 0 4}$ & $\mathbf{2 0 0 2}$ & $\mathbf{2 0 0 4}$ \\
\hline Cereal & No & 39.6 & 53.9 & 18.7 & 20.0 \\
Producer & Yes & 30.8 & 43.5 & 18.4 & 20.7 \\
\hline Industrial Crop & No & 27.2 & 39.8 & 16.6 & 20.4 \\
Producer & Yes & 39.6 & 53.1 & 19.2 & 19.2 \\
\hline Vegetable & No & 32.5 & 45.4 & 18.7 & 21.3 \\
Producer & Yes & 34.8 & 45.9 & 19.7 & 19.7 \\
\hline Fruit & No & 32.0 & 43.9 & 18.9 & 20.9 \\
Producer & Yes & 35.4 & 50.4 & 18.5 & 20.4 \\
\hline Technical & Received & 32.4 & 45.3 & 18.6 & 20.8 \\
Support Receiver & Not Received & 42.4 & 55.0 & 21.8 & 23.0 \\
\hline Credit User & Used & 32.0 & 44.2 & 18.5 & 20.8 \\
& Not Used & 39.7 & 52.4 & 20.6 & 20.6 \\
\hline ASC Member & Member & 30.6 & 43.7 & 17.8 & 20.5 \\
& Not Member & 44.4 & 57.4 & 19.9 & 20.1 \\
\hline Education Level & Illeterate & 26.4 & 37.8 & 16.5 & 20.5 \\
& Lit. And Pri. & 33.7 & 46.7 & 18.8 & 20.6 \\
& Primary + & 42.3 & 54.1 & 20.3 & 19.9 \\
\hline Sol
\end{tabular}

Source: Author's calculations from G.G. et. al. (2003 and 2005)

Figures in Table 7 justify our findings and comments on the coefficients of technical inefficiency variables. However, there are some important conclusions that could not have been reached by merely considering the coefficients. First of all, although the coefficients of 
DIS recipients, credit access, taking technical support and ASCU membership status were found to be ineffective on efficiency, one can observe that households that receive credit, take technical support or are ASCU members are considerably more efficient. Households that receive DIS are also more efficient even if the difference is not that noteworthy. Moreover, the gap between DIS receivers and the others has increased from 2002 to 2004.

Table 8 compares the mean efficiencies of DIS receivers that are in different land size groups. Two results are worth highlighting. Households that did not received DIS payments in less than 2 Hectares group are more efficient than the ones that received DIS payments, in 2002. Note that difference is greater than the sample average. Secondly, households that received DIS in the 20-50 Hectares group are drastically more efficient than those that did not receive DIS. The situation is reversed in 2004. DIS receivers of 20-50 Hectares group turn out to be less efficient, while less than 2 Hectares group became more efficient. The percentage of households that received DIS in each group explains these findings. Percentage of households that receive DIS increases by farm size. It is the highest for 20-50 Hectares group in 2002, while the gap is moderately closed in 2004. Share of households that received DIS is lowest in less than 2 Hectares group in both periods. Thus even if DIS receiving has a positive effect on efficiency, it is hard to observe this effect from mean efficiency of size groups.

Table 8: Mean efficiencies of DIS receivers and others according to farm size

\begin{tabular}{|c|c|c|c|c|c|c|c|}
\hline & \multicolumn{2}{|c|}{ Not Receiving DIS } & \multicolumn{2}{|c|}{ Receiving Dis } & \multicolumn{2}{|c|}{ All Producers } \\
\hline & & Mean & Std. Dev. & Mean & Std. Dev. & Mean & Std. Dev. \\
\hline \multirow{6}{*}{ ণั } & $0-2 \mathrm{Ha}$. & 33.8 & 19.8 & 31.8 & 17.1 & 33.1 & 18.9 \\
\hline & 2-5 Ha. & 31.0 & 17.9 & 31.5 & 16.9 & 31.3 & 17.4 \\
\hline & 5-10 Ha. & 31.2 & 18.2 & 32.9 & 18.5 & 32.2 & 18.4 \\
\hline & $10-20 \mathrm{Ha}$. & 31.7 & 19.6 & 32.8 & 19.4 & 32.5 & 19.4 \\
\hline & 20-50 Ha. & 32.1 & 20.7 & 38.5 & 20.2 & 36.4 & 20.5 \\
\hline & 50+ Ha. & 37.8 & 20.5 & 37.6 & 21.9 & 37.7 & 21.5 \\
\hline \multirow{6}{*}{ ర్రి } & 0-2 Ha. & 44.9 & 20.8 & 45.2 & 20.7 & 45.1 & 20.7 \\
\hline & 2-5 Ha. & 41.6 & 20.6 & 43.4 & 20.5 & 42.9 & 20.5 \\
\hline & 5-10 Ha. & 40.4 & 18.9 & 47.0 & 20.7 & 45.9 & 20.6 \\
\hline & 10-20 Ha. & 41.9 & 23.0 & 47.9 & 21.2 & 47.1 & 21.5 \\
\hline & 20-50 Ha. & 52.4 & 20.1 & 47.2 & 21.4 & 47.8 & 21.3 \\
\hline & $50+\mathrm{Ha}$. & 44.1 & 26.2 & 54.1 & 21.0 & 52.8 & 21.8 \\
\hline
\end{tabular}

Source: Author's calculations from G.G. et. al. (2003 and 2005)

\section{Conclusion}

The efficiency levels put forward an important integration problem across the country. The problem is more serious in the Eastern parts of the country. Besides, the gap between east and west works out to be increasing.

Secondly, sectors that have been subsidized historically by distortionary measures turn out to be inefficient. There seems to be slight but inadequate adjustments after the implementation of ARIP, especially when one considers the necessity, exigency and urgency of transformation in agricultural sector in the context of EU accession negotiations and Millennium Round of the WTO Negotiations.

The problems in the implementation of ARIP are reflected in results. First of all, ARIP could not reach small farmers and cereal producers, if DIS receiving are taken as an indicator of this. A drastically small percentage of small farmers are enrolled in DIS program compared the other farm groups. Secondly, the least developed parts of the country also cannot enjoy the benefits of ARIP sufficiently. Although DIS is revealed as being a better way of subsidizing farmers, it needs to be developed to reach the poorer farmers. 
Although outcomes of N-TIEM model support the need to increase the average farm size, the results of NN-TIEM model, which suggests that 2-5 Hectares size group is more efficient than the mid-sized farms, should be kept in mind. Besides, average farm size does not look like an urgent and serious problem for agricultural production.

The positive effect of irrigation on efficiency is another important conclusion derived from out analysis. However, we found that using electricity for irrigation hinders the effect of irrigation. Thus, canal irrigation increases the efficiency of irrigation.

Our findings supports that there is an excess employment of labor in agriculture. This is not surprising for a country where 33 percent of the employed labor force is in the agricultural sector in 2004. It is obvious that this situation cannot be sustained especially under the increased competition that will be imposed by multilateral agreements and EU accession in future. However as interactions of labor with technical inefficiency variables offers, rather than trying to "exile" people from agriculture, introducing policies that will create incentives for labor to move to the more efficient areas inside the agricultural sector would be both less costly and more productive.

A similar argument is also valid for land. Land is found to hinder the positive effects of most of the technical inefficiency variables on efficiency. The problem with land can be more challenging since it cannot be moved to the more efficient areas. The solution is likely to lie in making long term investments, to increase the quality of the land which will diminish the climate dependency of the crop production.

Modern inputs are found to be dominating the production process. In addition, this had been encouraged by governments in the past, especially by distorting the prices paid by the farmers. However, this can create serious environmental problems in the future. Although our analysis cannot exactly identify the magnitude of the problem, negative interactions of pesticides and fertilizers suggest that excessive use of these inputs may not only harm the environment, but also affects the productivity of the basic factors of production. 


\section{References}

Afriat S.N. (1972) Efficiency Estimation of Production Functions. International Economic Review, 13(3): 568-598. doi:10.2307/2525845

Aigner, D.J., Chu, S.F. (1968) On Estimating the Industry Production Function. American Economic Review, 58(4): 826-39. http://www.jstor.org/stable/1815535

Aigner, D.J., Lovell, C.A.K., Schmidt, P.J. (1977) Formulation and estimation of stochastic frontier production function models. Journal of Econometrics, 6: 21-37. doi:10.1016/0304-4076(77)90052-5

Akçay, Y. And Esengün, K. (1999) The Efficiency of Resource Allocation and Productivity in the Agricultural Farms in Kazova Region of Tokat Province, Turkish Journal of Agriculture and Forestry, 23:831-842

Akder, H., Kasnakoglu, H., Çakmak, E.H. (2000), Turkey: Sources of Growth in Turkish Agriculture, in Turkey: Country Economic Memorandum, Structural Reforms for Sustainable Growth, Background Papers, World Bank, Washington, DC.

Battese, G.E., Coelli, T.J. (1992) Frontier Production Functions, Technical Efficiency and Panel Data: With Application to Paddy Farmers in India. Journal of Productivity Analysis, 3(1-2): 153-169. doi:10.1007/BF00158774

Battese, G.E., Coelli, T.J. (1995) A model for technical inefficiency effects in a stochastic frontier production function for panel data. Journal of Empirical Economics, 20(2): 325-332. doi:10.1007/BF01205442

Batesse, G.E., Rao, D.S.P., O'Donnell, C.J. (2004) A Metafrontier Production Function for Estimation of technical Efficiencies and Technology gaps for Firms Operating Under Different Technologies, Journal of Productivity Analysis 21: 91-103. doi:10.1023/B:PROD.0000012454.06094.29

Batesse, G.E., Broca S.S. (1997) Functional Forms of Stochastic Frontier Production Functions and Models for Technical Inefficiency Effects: A comperative Study for Wheat Farmers in Pakistan, Journal of Productivity Analysis, 8: 395-414. doi:10.1023/A:1007736025686

Battese, G.E., Coelli, T.J., (1993) A stochastic frontier production function incorporating a model of technical inefficiency effects. Working Papers in Econometrics and Applied Statistics vol. 69, Department of Econometrics, University of New England, Armidale

Battese, G.E., Corra, G. (1977) Estimation of a Production Frontier Model with Application to the Pastoral Zone of Easter Australia. Australian Journal of Agricultural Economics, 21(3): 167-179. doi:10.1111/j.1467-8489.1977.tb00204.x

Chavas, J.P., Petrie R., Roth, M. (2005) Farm Household Production Efficiency: Evidence From the Gambia, American Journal of Agricultural Economics, 87(1): 160-179. doi:10.1111/j.0002-9092.2005.00709.x

Coelli, Rahman and Thirtle (2003) A Stochastic frontier approach to total factor productivity measurement in Bangladesh crop agriculture 1961-92, Journal of International Development, 15:321-333. doi:10.1002/jid.975

Cornwell, C., Schmidt, P., Sickles, R.C. (1990) Production Frontiers with Cross- Sectional and Time-Series Variations in Efficiency Levels. Journal of Econometrics, 46(1/2): 185-200. doi:10.1016/0304-4076(90)90054-W 
Çakmak, E.H. (2004) Structural Change and Market Opening in Turkish Agriculture, Paper presented in "Seminaire Analyse comparee des relations agricoles en libre-echange Nord-Sud" Monpellier

Çakmak, E.H., Akder, H. (2005) DTÖ ve AB'deki Gelismeler Isiginda 21. Yüzyilda Türkiye Tarimi, (in Turkish), TÜSIAD-T/2005-06/397, July, Istanbul: Lebib Yalkim Yayinevi

Çakmak, E.H., Dudu, H., Ocal, N., 2008, Turk Tarim Sektorunde Etkinlik: Yontem ve Hanehalki Duzeyinde Nicel Analiz [Efficiency in Turkish Agricultural Sector: Method and Farm Household Level Quantitative Analysis], (in Turkish) TEPAV Yayinlari: Ankara available at http://goo.gl/qIn4A

Çakmak, E.H., Tozanli, S. Dudu, H. Kirisçi E.N. (2004) Characterization of Agricultural And Agro-Industrial Sectors in Turkey, Report for the Project "Impacts of agricultural trade liberalization Between the EU and Mediterranean Countries" supported by Framework Program 6 of European Union, http://eumedagpol.iamm.fr/doc/reports/turquie_d3.pdf

Çakmak, E.H., Zaim, O. (1998) Labor and Land Productivity in Turkish Agriculture, in Employment in Agriculture Study, ed. Tümay Bulutay, Ankara: State Institute of Statistics Publications

Dudu, H. (2006) Efficiency in Turkish Agriculture: A Farm Household Level Analysis, Middle East Technical University, Department of Economics, unpublished M.Sc. Thesis

Fare, R., Grosskopf, S., Lovell, C.A.K. (1985) The Measurement of Efficiency of Production, Kluver-Nijhoff Publishing, Boston. doi:10.1007/978-94-015-7721-2

Farrell, M.J. (1957) The Measurement of Productive Efficiency, Journal of Royal Statistical Society, Series A, General. 120, Part 3: 253-281. doi:10.2307/2343100

G\&G Consulting, Baskent Unv. Development Foundation, TNS Siar JV (2003) Agricultural Reform Implementation Project Quantitative Household Survey Final Report

G\&G Consulting, Baskent Unv. Development Foundation, TNS Siar JV (2005) Agricultural Reform Implementation Project Quantitative Household Survey Final Report

Gabrielsen, A. (1975) On Estimating Efficient Production Functions Working Paper no A-35, Chr. Michelsen Institute, Department of Humanities and Social Sciences, Bergen, Norway.

Greene, W.M. (1980) Maximum likelihood Estimation of Econometric Frontier Functions. Journal of Econometrics, 13(1): 27-56. doi:10.1016/0304-4076(80)90041-X

Kepenek, Y., Yentürk, N. (2001) Türkiye Ekonomisi, 12th ed. Istanbul: Remzi Kitabevi

Kumbhakar, S.C. (1990) Production Frontiers, Panel Data and Time-Varying Technical Inefficiency. Journal of Econometrics, 46(1/2): 201-211. doi:10.1016/03044076(90)90055-X

Kumbhakar, S.C., Lovell, C.A.K. (2000) Stochastic Frontier Analysis, Cambridge University Press, Cambridge. doi:10.1017/CBO9781139174411

Lundell, M., Lampietti, J., Pertev, R., Pohlmeier, L., Akder, H., Ocek, E., Jha, S., (2004), Turkey: A Review of the Impact of The Reform of Agricultural Sector Subsidization, World Bank: Washington, D.C. 
Meeusen, W., Van den Broeck, J. (1977) Efficiency Estimation from Cobb-Douglas production functions with composed error. International Economic Review, 18: 435444. doi: $10.2307 / 2525757$

Murillo-Zamarano, L.R. (2004) Economic Efficiency and Frontier Techniques, Journal of Economic Surveys, 18(1): p. 33-77. doi:10.1111/j.1467-6419.2004.00215.x

Özkan, B. Akçaöz, H., Fert, C. (2004) Energy input-output Analysis in Turkish Agriculture, Renewable Energy, 29:39-5. doi:10.1016/S0960-1481(03)00135-6

Pitt, M.M., Lee, L.F. (1981) The Measurement and Sources of Technical Inefficiency in the Indonesian Weaving Industry, Journal of Development Economics, 9: 43-64. doi: 10.1016/0304-3878(81)90004-3

Richmond, J. (1974) Estimating the Efficiency of Production. International Economic Review, 15: 515-521. doi:10.2307/2525875

Schmidt, P., Sickles, R.C. (1984) Production Frontiers and Panel Data. Journal of Business and Economic Statistics, 2: 299-326. doi:10.1080/07350015.1987.10509583

Mahmud, S.F., Demir, N. (2003) Agro-Climatic Conditions and Regional Inefficiencies in Agriculture, Canadian Journal of Agricultural Economics, 50:269-280. doi:10.1111/j.1744-7976.2002.tb00337.x

Mahmud, S.F., Demir, N.,(1999) Regional Technical Efficiency Differentials in the Turkish Agriculture: A Note, Indian Economic Review, 33:197-206

Toksoy, D., Ayyildiz, H., (2004) Measuring the Marketing Performances of State Nurseries in Turkey: Examples of Eastern Anatolia and Black Sea Region Nurseries, Turkish Journal of Agriculture and Forestry, 28:443-456

Uzunlu, V., Bayaner, A. , Beniwal, P.S. (1999), Problem Identification and Priority Setting in Agricultural Research: The Case of The Eastern Margin of Central Anatolia, Turkish Journal of Agriculture and Forestry, 23:679-686

$\mathrm{Xu}$, X., Jeffrey, S.R. (1998) Efficiency and technical progress in traditional and modern agriculture: evidence from rice production in China, Journal of Agricultural Economics, 18:157-165. doi:10.1016/S0169-5150(98)80004-2 